\title{
ПОЛУЧЕНИЕ В ЦЕМЕНТИРОВАННОМ СЛОЕ СТАЛЕЙ МЕТАСТАБИЛЬНОГО ОСТАТОЧНОГО АУСТЕНИТАДЛЯ ПОВЫШЕНИЯ ИХ АБРАЗИВНОЙ ИЗНОСОСТОЙКОСТИ
}

\begin{abstract}
Актуальность работь. Повышение долговечности деталей и инструмента, выходящих из строя из-за абразивного износа, является актуальной проблемой. Получение в структуре поверхностного слоя сталей, из которых они изготовлены, метастабильного остаточного аустенита и реализация динамического деформационного мартенситного превращения - ДДМП (эффект самозакалки при нагружении - СЗН) является одним из перспективных направлений решения этой проблемы.

Цель работы - определить рациональные режимы термообработки, обеспечивающие значительное повышение абразивной износостойкости исследованных сталей 45Г, ДИ42, 65Г, М76 после иементации за счет получения в структуре поверхностного слоя наряду с другими составляющими повышенного количества метастабильного остаточного аустенита и реализации эффекта СЗН.

Методы исследования. Для исследований образиы подвергались изементации в твердом карбюризаторе при $930{ }^{\circ} \mathrm{C} 10$ ч. Температурный интервал нагрева под закалку составлял 800-1150 ${ }^{\circ}$ С. После закалки стали отпускали при $180{ }^{\circ} \mathrm{C} 1$ ч. Применялись дюрометрический, металлографический методы исследования. Фазовый состав определялся методом рентгеновского анализа с использованием дифрактометра ДРОН-3. Испытания на абразивный износ осуществлялись по методу Бринелля-Хауорта.

Результаты. Наиболее высокая относительная абразивная износостойкость получена у исследованных цементированных сталей после закалки с определенной для каждой из них температуры, более высокой, чем типовая, и низкого отпуска, когда в структуре наряду с отпущенным мартенситом и карбидами в структуре присутствует 25-45 \%метастабильного аустенита, претерпевающего ДДМП.

Научная новизна. Предложено для повышения абразивной износостойкости исследованных сталей с повышенным содержанием углерода их иееентировать, после чего проводить нагрев под закалку до определенной для каждой стали температуры, зависящей от ее химического состава, обеспечивающей получение после закалки и низкого отпуска оптимального количества остаточного аустенита и степени его стабильности.
\end{abstract}

Практическая ценность. Для каждой исследованной стали, обычно не подвергающейся науглероживанию, после цементации определены температуры нагрева под закалку, обеспечивающие значительное повыщение абразивной износостойкости за счет получения в структуре поверхностного слоя наряду с другими составляющими повышенного количества метастабильного остаточного аустенита.

Ключевые слова: ичементация, закалка, мартенсит деформации, метастабильный остаточный аустенит, абразивная износостойкость, самозакалка при нагружении.

\section{Введение}

Повышение долговечности деталей и инструмента, выходящих из строя из-за абразивного износа, является актуальной проблемой. Во многих случаях ее решают применением сложнолегированных сталей и чугунов, содержащих зачастую дорогие легирующие элементы (никель, молибден, вольфрам, ниобий и др.), а также упрочняющих технологий, обеспечивающих получение высокой твердости поверхности.

В последние годы получает все большее распространение предложенный в работе [1] принцип создания в сплавах многофазной метастабильной структуры с обязательным получением в ней различного количе-

() Малинов Л. С., Малышева И. Е., Бурова Д. В., 2020 DOI 10.15588/1607-6885-2020-1-8 ства и степени стабильности аустенита, претерпевающего ДДМП при нагружении (эффект СЗН), для повышения сопротивления сплавов разрушению. Это позволяет использовать их собственный ресурс, которым является метастабильный аустенит. На развитие ДДМП расходуется значительная часть энергии внешнего воздействия и, соответственно, меньшая ее доля идет на разрушение материала [1-4]. Кроме того, в процессе образования при нагружении мартенсита происходит не только упрочнение, но и релаксация микронапряжений, вследствие чего повышается работоспособность микрообъемов сплава. При этом важно с учетом исходных химического и фазового составов сплавов и ус- 
ловий нагружения управлять соотношением структурных составляющих и развитием ДДМП при изнашивании [1-4]. Одновременно с этим следует использовать и другие известные механизмы упрочнения и сопротивления разрушению [5]. В процессе изнашивания происходят разнообразные изменения структуры. Она сильно диспергируется, приобретая зачастую нанокрсталлическое строение [6], изменяется плотность дислокаций, происходит динамическое деформационное старение мартенсита и аустенита (ДДС). Эти изменения вызывают переход в новое, более равновесное состояние. Выполняется принцип Ле Шаталье, согласно которому система реагирует на внешнее воздействие таким образом, что относительный уровень этого воздействия снижается, и система, как бы адаптируется к нему. Данная трансформация реализуется эволюционным путём постепенного перехода от одного структурного состояния к другому, в результате чего происходит процесс диссипации энергии, повышающий сопротивление материала к разрушению, что и обеспечивает ему свойства существенно более высокие, чем обычно достигаемые в настоящее время [7]. Наиболее важную роль в адаптации и формировании свойств сталей и чугунов с многофазной метастабильной структурой играет ДДМП. Остаточный метастабильный аустенит по существу является внутренним ресурсом самого материала, обеспечивающим ему самозащиту от разрушения при испытаниях свойств или эксплуатации [14]. Образование мартенсита в процессе изнашивания создает сжимающие напряжения на поверхности, препятствующие разрушению. Кроме того, при возникновении мартенситных кристаллов может снижаться плотность дислокаций за счет их стока на поверхность раздела мартенсит-аустенит. Важную роль должны играть, как уже отмечалось, сильное диспергирование структуры и динамическое деформационное старение.

\section{Анализ публикаций по теме работы}

Впервые идея использования мартенситных превращений, протекающих при нагружении в процессе испытаний свойств или эксплуатации, была высказана и реализована при разработке метастабильных аустенитных кавитационностойких сталей И.Н. Богачевым и Р. И. Минцем $[8,9]$. Это явилось началом одного из основных направлений в материаловедении XXI века по созданию материалов с метастабильной структурой, самоорганизующейся под внешним воздействием (смарт материалы) и технологий, обеспечивающих получение такой структуры [10].

В работе изучена возможность повышения абразивной износостойкости сталей 45Г ДИ42, 65Г, М76, применяемых для деталей, работающих в данных условиях. Эти стали обычно не подвергаются цементации. Обычно эта химико-термическая обработка применяется для малоуглеродистых сталей [5]. Между тем, у исследованных сталей она позволяет в сочетании с рациональными режимами термообработки получать в поверхностном слое структуру, состоящую из отпущенного мартенсита, карбидов и метастабильного остаточного аустенита. Работы по применению этой технологии для сталей с повышенным содержанием углерода различных систем легирования с реализацией эффекта СЗН немногочисленны [2-4]. Согласно предыдущим исследованиям, проведенным на других, чем в данной работе, сталях с повышенным содержанием углерода, эта технология обеспечивает повышенную абразивную износостойкость. Однако из-за недостаточной информации по данному вопросу она еще не нашла применения в промышленности. Следует отметить, что во многих работах положительная роль остаточного аустенита в повышении абразивной износостойкости отрицается или вообще не рассматривается. Именно поэтому в учебной, справочной литературе и заводских инструкциях обосновывается необходимость получения после цементации и термообработки структуры отпущенного мартенсита и карбидов, обеспечивающей наиболее высокую твердость. Допускается иметь не более 15 \% остаточного аустенита, поскольку его большее количество снижает твердость, соответственно, что, как считается общепризнанным, износостойкость. На некоторых заводах большее, чем это, количество аустенита рассматривается как браковочный признак [11]. Для уменьшения или полного устранения остаточного аустенита в структуре применяют различные способы: подстуживание при закалке с цементационного нагрева, обработку холодом, промежуточный высокий отпуск с последующей закалкой из межкритического интервала температур и др. [12].

\section{Методы и материалы}

Определялись рациональные режимы термообработки, обеспечивающие значительное повышение абразивной износостойкости исследованных сталей 45Г, ДИ42, 65Г, М76 после цементации за счет получения в структуре поверхностного слоя наряду с другими составляющими повышенного количества метастабильного остаточного аустенита и реализации эффекта самозакалки при нагружении.

Исследовались структура, фазовый состав, твердость и абразивная износостойкость сталей 45Г, ДИ42, 65Г и М76 после цементации, закалки с различных температур и низкого отпуска. Химический состав исследованных сталей приведен в табл. 1.

Цементацию проводили по типовой технологии в твердом карбюризаторе при $930{ }^{\circ} \mathrm{C} 10$ ч. Температурный интервал нагрева под закалку составлял 800-1150 ${ }^{\circ} \mathrm{C}$. Ниже для каждой стали он уточнен. После закалки стали отпускали при $180{ }^{\circ} \mathrm{C} 1$ ч. Применяли дюрометрический, металлографический методы исследования. Фазовый состав определялся методом рентгеновского анализа с использованием дифрактометра ДРОН-3.

Испытания на абразивный износ исследованных сталей осуществлялись по методу Бринелля-Хауорта. Эталоном для стали 45Г служила сталь 45 в отожженном 
Таблица 1 - Химический состав исследованных сталей

\begin{tabular}{|c|c|c|c|c|c|c|c|c|c|c|}
\hline \multirow{2}{*}{ Марка } & \multicolumn{10}{|c|}{ Химический состав, масс. \% } \\
\hline & $\mathrm{C}$ & $\mathrm{Mn}$ & $\mathrm{Si}$ & $\mathrm{Cr}$ & Mo & $\mathrm{W}$ & V & $\mathrm{Ni}$ & $\mathrm{S}$ & $\mathrm{P}$ \\
\hline $45 \Gamma$ & 0,45 & 0,97 & 0,37 & 0,25 & - & - & - & 0,25 & 0,035 & 0,035 \\
\hline ДИ42 & 0,49 & 0,76 & 1,14 & 1,77 & 0,48 & 0,24 & - & 0,34 & 0,010 & 0,18 \\
\hline $65 \Gamma$ & 0,67 & 1,05 & 0,25 & - & - & - & - & - & 0,030 & 0,035 \\
\hline M76 & 0,77 & 0,96 & 0,26 & - & - & - & - & - & 0,015 & 0,020 \\
\hline
\end{tabular}

состоянии, для стали ДИ42 - та же сталь после реализуемой на производстве технологии, включающей закалкус $930{ }^{\circ} \mathrm{C}$ и отпуск при $300^{\circ} \mathrm{C} 1$ ч, для сталей 65 Г и М76эти же стали после типовой термообработки, включающей закалку и средний отпуск. Ниже приведены данные о влиянии температуры нагрева под закалку на количество остаточного аустенита, микроструктуру, твердость и абразивную износостойкость исследованных сталей.

\section{Результаты экспериментов и их обсуждение}

Образцы цементированной стали 45Г закаливали с температур в интервале от 800 до $1000^{\circ} \mathrm{C}$ с шагом $50{ }^{\circ} \mathrm{C}$ и отпускали при $180{ }^{\circ} \mathrm{C} 1$ час. С повышением температуры нагрева под закалку в цементированном поверхностном слое увеличивается доля остаточного аустенита, что является следствием все более полного растворения карбидов в аустените и снижения точки $\mathrm{M}_{\text {н }}$ (табл. 2).
Металлографический анализ подтвердил изменения в структуре стали 45Г при повышении температуры нагрева под закалку (рис. 1). В результате закалки от $800^{\circ} \mathrm{C}$ после низкого отпуска структура цементированного слоя представляет собой отпущенный мартенсит, карбиды и небольшое количество остаточного аустенита (10\%). Повышение температуры нагрева под закалку до $1000{ }^{\circ} \mathrm{C}$ привело к полному растворению карбидов в аустените и, как следствие, увеличению количества остаточного аустенита до $235 \%$.

Относительная абразивная износостойкость цементированной стали 45 Г после закалки с $800{ }^{\circ} \mathrm{C}$ и низкого отпуска имеет наименьший уровень $(\varepsilon=1,9)$, несмотря на наиболее высокую твердость (60 HRC). При повышении температуры аустенитизации от 800 до $900{ }^{\circ} \mathrm{C}$ износостойкость возрастает, достигая максимума $(\varepsilon=2,8)$, и снижается при нагреве под закалку до более высоких температур (табл. 2).

Таблица 2 - Влияние температуры нагрева под закалку на количество остаточного аустенита в поверхностном слое, твердость и относительную абразивную износостойкость предварительно цементированных образцов стали 45Г

\begin{tabular}{|c|c|c|c|}
\hline Температура, ${ }^{\circ} \mathrm{C}$ & $\mathrm{A}_{\text {ост }}, \%$ & $\begin{array}{c}\text { Твердость, } \\
\text { НRC }\end{array}$ & $\begin{array}{c}\text { Относительная абразивная } \\
\text { износостойкость, } \varepsilon\end{array}$ \\
\hline 800 & 10 & 60 & 1,9 \\
\hline 850 & 18 & 59 & 2,4 \\
\hline 900 & 25 & 58 & 2,8 \\
\hline 950 & 30 & 54 & 2,6 \\
\hline 1000 & 35 & 50 & 2,3 \\
\hline
\end{tabular}

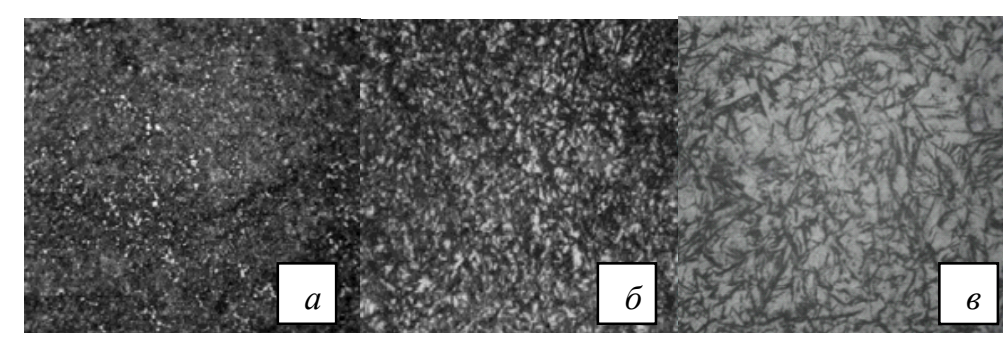

Рис. 1. Микроструктура поверхности цементированной стали 45Г после закалки с различных температур, $\times 500$ :

$$
a-\mathrm{c} 800{ }^{\circ} \mathrm{C} ; \sigma-\mathrm{c} 900{ }^{\circ} \mathrm{C} ; 6-\mathrm{c} 1000^{\circ} \mathrm{C}
$$


Однако даже после закалки с $1000{ }^{\circ} \mathrm{C}$ и низкого отпуска ее уровень ( $\varepsilon=2,3$ ) выше, чем после закалки с $800{ }^{\circ} \mathrm{C}$, несмотря на существенное снижение твердости (50 HRC). Приведенная закономерность объясняется тем, что после закалки цементированной стали 45Г с $900{ }^{\circ} \mathrm{C}$ и низкого отпуска в поверхностном слое формируется наиболее благоприятная структура: отпущенный мартенсит с повышенным содержание углерода, карбиды, не растворившиеся при аустенизации, и остаточный аустенит (25\%) оптимальной степени стабильности по отношению к ДДМП, реализующемуся при абразивном воздействии. Дифрактограммы, полученные до и после изнашивания свидетельствуют о том, что весь остаточный аустенит превратился в мартенсит деформации (рис. 2).

Закалка с $1000{ }^{\circ} \mathrm{C}$ (отпуск $180^{\circ} \mathrm{C}, 1$ ч) из-за полного растворения карбидов в аустените, увеличивая количество остаточного аустенита в структуре, обусловливает повышение его стабильности к ДДМП. Об этом свидетельствует данные рентгеновского анализа, показывающие существенное снижение прироста мартенсита деформации на изношенной поверхности $(\Delta \mathrm{M} 10 \%)$ по сравнению с тем, которое наблюдалось после закалки с $900{ }^{\circ} \mathrm{C}(\Delta \mathrm{M} 25 \%)$. Кроме того, после указанной термообработки при повышенном количестве остаточного аустенита снижается доля мартенсита отпуска и отсутствуют карбиды, что также отрицательно сказывается на абразивной износостойкости.
Основные закономерности в изменении фазового состава, структуры и абразивной износостойкости при повышении температуры нагрева под закалку рассмотренной выше стали наблюдаются и у стали ДИ42. С повышением температуры нагрева под закалку у этой стали увеличивается доля остаточного аустенита в поверхностном слое, а количество карбидов и отпущенного мартенсита уменьшается, что вызывает снижению твердости (табл. 3). Наиболее высокую относительную абразивную износостойкость ( $\varepsilon=2,2)$ цементированная сталь имеет после закалки с $1100^{\circ} \mathrm{C}$ и последующего отпуска при $180{ }^{\circ} \mathrm{C}$ (табл. 3). Такая высокая температура нагрева под закалку необходима для растворения в аустените части труднорастворимых карбидов вольфрама, молибдена, ванадия, содержащихся у рассматриваемой стали в цементированном слое, и получения в его структуре повышенного количества метастабильного аустенита. Наиболее высокое сопротивление изнашиванию у стали ДИ42 достигается получением в структуре наряду с отпущенным мартенситом и карбидами $\sim 45 \%$ остаточного аустенита (рис. 3 ).

Следует отметить, что при изнашивании большая часть метастабильного остаточного аустенита (35\%) превращается в мартенсит деформации, о чем свидетельствуют дифрактограммы (рис. 4).

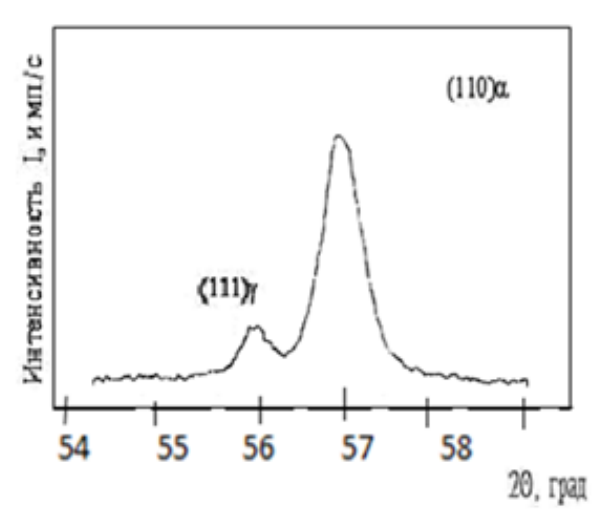

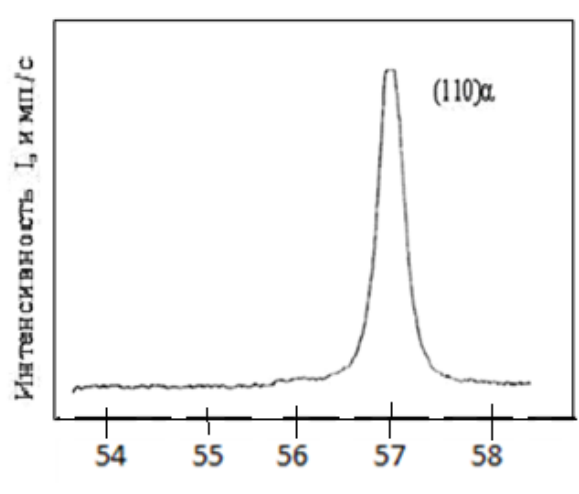

$\sigma$

Рис. 2. Дифрактограммы образцов цементированной стали 45 Г после закалки с $900{ }^{\circ} \mathrm{C}$ и отпуска $180{ }^{\circ} \mathrm{C}, 1$ ч до (a) и после изнашивания (б)

Таблица 3 - Влияние температуры нагрева под закалку на твердость и относительную абразивную износостойкость, предварительно цементированной стали ДИ42

\begin{tabular}{|c|c|c|c|}
\hline Температура, ${ }^{\circ} \mathrm{C}$ & $\mathrm{A}_{\text {ост }} \%$ & Твердость, НRC & $\begin{array}{c}\text { Относительная абразивная } \\
\text { износостойкость, } \varepsilon\end{array}$ \\
\hline 930 & 10 & 60 & 1,0 \\
\hline 1000 & 25 & 57 & 1,9 \\
\hline 1050 & 45 & 55 & 2,2 \\
\hline 1150 & 55 & 53 & 2,0 \\
\hline
\end{tabular}



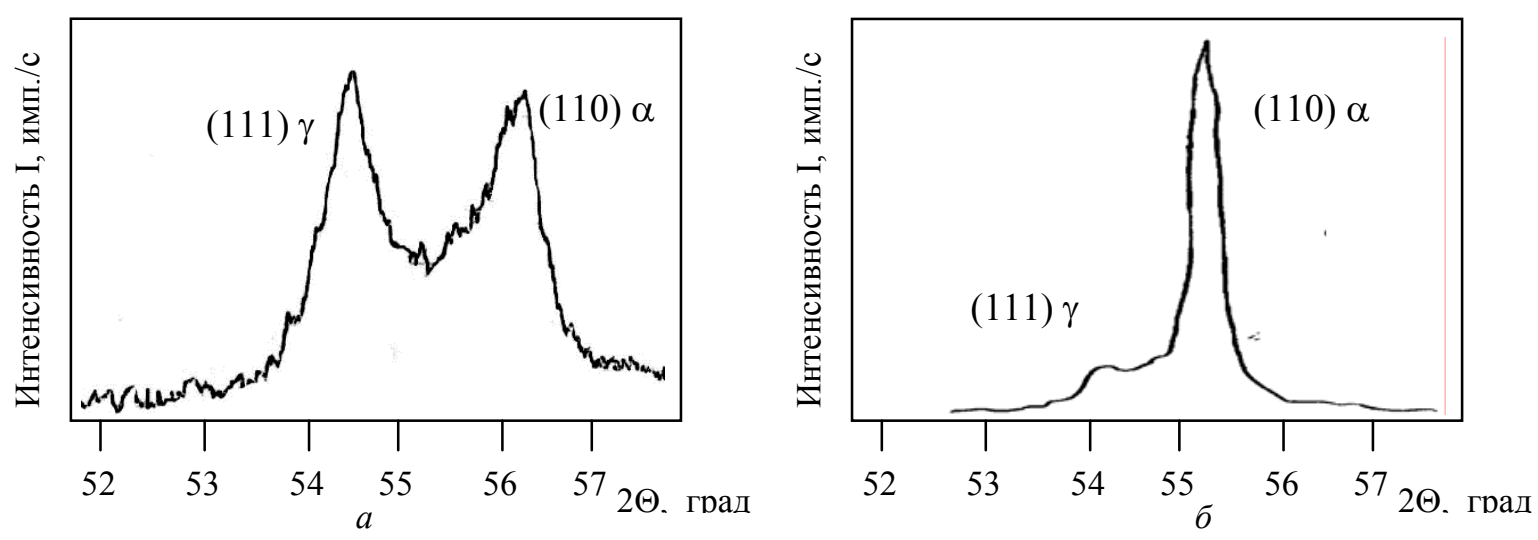

Рис. 4. Дифрактограммы стали ДИ42 после цементации и последующей закалки с $1050{ }^{\circ} \mathrm{C}$, отпуск $180{ }^{\circ} \mathrm{C}, 1$ ч:

$$
\left.a \text { - до износа ( } \mathrm{A}_{\text {ост }} \sim 45 \%\right), \sigma \text { - после износа }\left(\mathrm{A}_{\text {ост }} \sim 10 \%\right)
$$

Закалка с более высокой температуры $\left(1150^{\circ} \mathrm{C}\right)$, чем оптимальная, несколько снижает абразивную износостойкость стали ДИ42. Это обусловлено уменьшением в структуре цементированного слоя стали доли отпущенного мартенсита, карбидов и повышением количества и стабильности остаточного аустенита по отношению к ДДМП, что уменьшает его роль в снижении энергии внешнего воздействия, идущей на разрушение. Однако и в этом случае абразивная износостойкость в 2 раза превышает уровень, достигаемый после типовой термообработки.

Было изучено влияние цементации сталей $65 \Gamma$, М76 и последующей термообработки, включающей закалку с температур в интервале $800-950{ }^{\circ} \mathrm{C}$ и отпуск при $180{ }^{\circ} \mathrm{C} 1$ ч, на твердость и относительную абразивную износостойкость сталей с повышенным содержанием углерода. Полученные данные приведены в табл. 4. Из них следует, что наиболее высокая относительная абразивная износостойкость получена у цементированных сталей 65 Г и М76 после закалки с $900^{\circ} \mathrm{C}$ и низкого отпуска, когда в структуре наряду с отпущенным мартенситом и карбидами в структуре присутствует 25-30 \% метастабильного аустенита, претерпевающего ДДМП.

Полученные данные для сталей 65Ги М76 так же, как и для выше рассмотренных сталей, подтверждают целесообразность их цементации и закалки с более высоких, чем это принято температур, для увеличения абразивной износостойкости. При этом важную роль, как и в выше приведенных случаях, играет получение структуры, в которой наряду с отпущенным мартенситом и карбидами присутствует метастабильный аустенит.

\section{Выводы}

1. Для получения высокого уровня абразивной износостойкости у сталей со средним и повышенным содержанием углерода, их следует цементировать перед закалкой и низким отпуском.

2. Наиболее высокое сопротивление абразивному изнашиванию достигается у исследованных цементи-
Таблица 4 - Влияние температуры нагрева под закалку и отпуска при $180^{\circ} \mathrm{C} 1$ ч цементированных сталей $65 Г$ и М76 на их твердость и абразивную износостойкость

\begin{tabular}{|c|c|c|c|}
\hline \multirow{2}{*}{ Сталь } & $\begin{array}{c}\text { Температура, } \\
{ }^{\circ} \mathrm{C}\end{array}$ & $\begin{array}{c}\text { Твердость, } \\
\text { НRC }\end{array}$ & $\begin{array}{c}\text { Относительная } \\
\text { износо- } \\
\text { стойкость, } \varepsilon\end{array}$ \\
\hline \multirow{3}{*}{65 Г } & 800 & 60 & 1,8 \\
\cline { 2 - 4 } & 850 & 57 & 2,1 \\
\cline { 2 - 4 } & 900 & 53 & 2,5 \\
\hline \multirow{3}{*}{ M76 } & 950 & 49 & 2,3 \\
\cline { 2 - 4 } & 800 & 61 & 1,9 \\
\cline { 2 - 4 } & 850 & 58 & 2,3 \\
\cline { 2 - 4 } & 900 & 56 & 2,6 \\
\hline
\end{tabular}

рованных сталей при получении у них после термообработки в поверхностном слое многофазной структуры, в которой наряду с отпущенным мартенситом и карбидами образуется 25-45 \% метастабильного остаточного аустенита, превращающегося в мартенсит деформации при абразивном воздействии.

3. После цементации нагрев под закалку следует проводить до определенной для каждой стали температуры, зависящей от ее химического состава, обеспечивающей получение после закалки и низкого отпуска оптимального количества остаточного аустенита и степени его стабильности.

\section{Списоклитературы}

1. Малинов Л. С. Разработка экономнолегированных высокопрочных сталей и способов упрочнения с использованием принципа регулирования мартенситных превращений : дис. ... докт. техн. наук : 05.16.01/ Л. С. Малинов. - Екатеринбург, 1992. - 381 с.

2. Малинов Л. С. Экономнолегированные сплавы с мартенситными превращениями и упрочняющие технологии / Л. С. Малинов, В. Л. Малинов. - Харьков : ННЦ ХФТИ, 2007. - $352 \mathrm{c.}$

3. Малинов Л. С. Ресурсосберегающие экономнолегированные сплавы и упрочняющие технологии, обеспечивающие эффект самозакалки / Л. С. Малинов, В. Л. Ма- 
линов. - Мариуполь. - Изд-во «Рената», 2009. - 568 с.

4. Малинов Л. С. Абразивная износостойкость сплавов с метастабильным аустенитом / Л. С. Малинов, И. Е. Малышева. - Мариуполь : ПГТУ, 2019. - 217 с.

5. Гольдштейн М. И. Специальные стали / М. И. Гольдштейн, С. В. Грачев, Ю. Г. Векслер. - М. : МИСИС, 1999. 408 c.

6. Коршунов Л. Г. Прочностные свойства нанокристаллических структур, формирующихся в сталях и сплавах при абразивном и адгезионном изнашивании / Л. Г. Коршунов, А. В. Макаров, Н. Л. Черненко // В сб. трудов «Нанотехнологии и физика функциональных нанокристаллических материалов». - Екатеринбург : УРО РАН. 2005. - T. 1. - С. 288-305.

7. Малинов Л. С. Стали и чугуны с метастабильным аустенитом и эффектом самозакалки при нагружении - разновидность адаптационных материалов, повышающих свои свойства при внешнем воздействии за счет самоор- ганизации структуры / Л. С. Малинов // Металл и литье Украины. - 2003. - № 11. - С. 3-9.

8. Богачев И. Н. Кавитационное разрушение углеродистых сплавов / И. Н. Богачев, Р. И. Минц. - М. : Машгиз, 1959. $-110 \mathrm{c}$.

9. Богачев И. Н. Кавитационное разрушение и кавитационно-стойкие сплавы / И. Н. Богачев. - М. : Металлургия, 1972. - 189 с.

10. Прусаков Б. А. Проблемы материалов в ССІ веке (обзор) / Б. А. Прусаков // МиТОМ. - 2001. - № 1. - С. 3-5.

11 Зинченко В. М. Влияние остаточного аустенита на механические свойства цементованных сталей / В. М. Зинченко, Б. В. Георгиевская, В. А. Оловянишников // МиTOM. - 1987. - № 12. - С. 25-29.

12. Основы термической обработки стали / [М. А. Смирнов, В. М. Счастливцев, Л. Г. Журавлев]. - М. : Наука и технологии, 2012. -519 с.

Одержано 22.12.2020

Малінов Л. С., Малишева І. Ю., Бурова Д. В. Одержання в цементованому шарі сталей метастабільного залишкового аустеніту для підвищення їх абразивної зносостійкості

Актуальність роботи. Підвищення довговічності деталей і інструменту, щзо виходять з ладу через абразивний знос, є актуальною проблемою. Отримання в структурі поверхневого шару сталей, з яких вони виготовлені, метастабільного залишкового аустеніту і реалізація динамічного деформаційного мартенситного перетворення - ДДМП (ефект самогартування при навантаженні - СЗН) $є$ одним з перспективних напрямків вирішення цієї проблеми.

Мета роботи - визначити раціональні режими термообробки, щзоб забезпечити значне підвищення абразивної зносостійкості досліджених сталей 45Г, ДІ42, 65Г, М76 після цеементації за рахунок отримання в структурі поверхневого шару поряд з іншими складовими підвищеної кількості метастабільного аустеніту і реалізації ефекту С 3 .

Методи дослідження. Для досліджень зразки піддавалися цементачії в твердому карбюризаторі при $930{ }^{\circ} \mathrm{C}$ 10 год. Температурний інтервал нагрівання під гартування становив 800-1150 ${ }^{\circ} \mathrm{C}$. Після гартування сталі відпускали при $180^{\circ} \mathrm{C} 1$ год. Застосовувалися дюрометичний, металографічний методи дослідження. Фазовий склад визначався методом рентгенівського аналізу з використанням дифрактометру ДРОН-3. Випробування на абразивний знос здійснювалися за методом Бринелля-Хауорта.

Результати. Найбільш висока відносна абразивна зносостійкість отримана у досліджених цуементованих сталей після гартування з певною для кожної з них температури, вищої, ніж типова, і низького відпуску, коли в структурі поряд з відпущеним мартенситом і карбідами в структурі присутнє 25-45 \%метастабільного аустеніту, щзо зазнає ДДМП.

Наукова новизна. Запропоновано для підвищення абразивної зносостійкості досліджених сталей $з$ підвищеним вмістом вуглецюю їх цеементувати, після чого проводити нагрів під гартування до певної для кожної сталі температури, яка залежить від ї̈ хімічного складу, щчо забезпечує отримання після гартування та низького відпуску оптимальної кількості залишкового аустеніту і ступеня його стабільності.

Практична цінність. Для кожної дослідженої сталі, яка зазвичай не піддається навуглецюванню, після цементації визначені температури нагріву під гартування, щоб забезпечити значне підвищення абразивної зносостійкості за рахунок отримання в структурі поверхневого шару поряд з іншими складовими підвищеної кількості метастабільного аустеніту.

Ключові слова: изементація, гартування, мартенсит деформації, метастабільний залииковий аустеніт, абразивна зносостійкість, самозагартування при навантаженні.

Malinov L., Malysheva I., Burova D. Obtaining metastable residual austenite in the cemented layer of steels to increase their abrasive wear resistance

Work relevance. Increasing the durability of parts and tools that fail due to abrasive wear is an urgent problem. Obtaining in the structure of the surface layer of steels from which they are made, metastable retained austenite and the implementation of the dynamic deformation martensitic transformation - DDMT (self-quenching effect under loading $-S Q L)$ is one of the promising directions for solving this problem. 
Purpose of work - to determine rational modes of heat treatment that provide a significant increase in the abrasive wear resistance of the investigated steels 45G, DI42, 65G, M76 after carburizing due to the formation of a surface layer in the structure along with other components of an increased amount of metastable residual austenite and the implementation of the SQL effect.

Research methods. For research, the samples were carburized in a solid carburizer at $930^{\circ} \mathrm{C}$ for $10 \mathrm{~h}$. The temperature range of heating for hardening was $800-1150^{\circ} \mathrm{C}$. After quenching, the steel was tempered at $180^{\circ} \mathrm{C}$ for 1 hour. Durometric and metallographic research methods were used. The phase composition was determined by $X$-ray analysis using a DRON-3 diffractometer. Abrasion tests were carried out using the Brinell-Howorth method.

Results. The highest relative abrasive wear resistance was obtained for the studied case-hardened steels after quenching at a certain temperature for each of them, higher than the standard one, and low tempering, when the structure, along with tempered martensite and carbides, contains 25-45\% of metastable austenite in the structure $D D M T$.

Scientific novelty. To increase the abrasive wear resistance of the investigated steels with an increased carbon content, it is proposed to cement them, and then heat them up for hardening to a temperature determined for each steel, depending on its chemical composition, which ensures the optimal amount of retained austenite and the degree of its stability after quenching and low tempering.

Practical value. For each steel under study, which is usually not subjected to carburization, after carburizing, the heating temperatures for hardening are determined, which provide a significant increase in abrasive wear resistance due to the formation of a surface layer in the structure, along with other components of an increased amount of metastable residual austenite.

Key words: cementation, quenching, tempering martensite, metastable residual austenite, abrasive wear resistance, self-quenching effect under loading. 